\title{
Relationship between the Hydrophobicity of Cations and the Cationic Response of a Plasticized Poly(vinyl chloride) Membrane Electrode with no Added Ion-Exchanger
}

\author{
Takashi MaSadome, ${ }^{* 1}$ Toshihiko Imato, ${ }^{* 2 \dagger}$ Shin-ichi WaKIDA, ${ }^{* 3}$ Kunishige HigaShI, ${ }^{* 3}$ \\ and Yasukazu ASANO*4 \\ *1 Department of Chemical Science and Engineering, Ariake National College of Technology, \\ Higashi-Hagio, Omuta, Fukuoka 836-8585, Japan \\ *2 Department of Chemical Systems and Engineering, Graduate School of Engineering, Kyushu University, \\ Hakozaki, Higashi, Fukuoka 812-8581, Japan \\ *3 Department of Energy and the Environment, Osaka National Research Institute, Agency of Industrial Science \\ and Technology, Ministry of International Trade and Industry, Midorigaoka, Ikeda, Osaka 563-8577, Japan \\ *4 Laboratory of Chemistry, Department of General Education, Ariake National College of Technology, \\ Higashi-Hagio, Omuta, Fukuoka 836-8585, Japan
}

\begin{abstract}
The potential response of an electrode based on an $o$-nitrophenyl octyl ether (o-NPOE)-plasticized poly(vinyl chloride) (PVC) membrane with no added ion-exchanger to several cations of different hydrophobicity was examined. Furthermore, the hydrophobicity of the cations was evaluated by measuring the selectivity coefficient, $K_{\mathrm{Na} \text {,cation, }}^{\text {Pot }}$ of a sodium ion-selective electrode based on an $o$-NPOE-plasticized PVC membrane containing a cation exchanger, since the selectivity coefficient is closely related to hydrophobicity of the ions. From these results, the $o$-NPOE-plasticized PVC membrane electrode with no added ion-exchanger showed a Nernstian response to the cations for which the sodium ionselective electrode has a selectivity coefficient, $K_{\mathrm{Na}, \text { cation }}^{\mathrm{Pot}}$, of more than $10^{6.0}$. In addition, an electrode based on only the plasticizer ( $o$-NPOE) was fabricated by using an ion-sensitive field-effect transistor (ISFET); the response of the electrode to the cations was examined in order to evaluate the contribution of the plasticizer, itself, to the electrode response of the PVC membrane electrode with no added ion-exchanger. From the response of the $o$-NPOE-plasticized PVC membrane electrode and that of the ISFET electrode based on only the plasticizer to the cations, the response mechanism of the $o$ NPOE-plasticized PVC membrane electrode with no added ion-exchanger to the hydrophobic cations is discussed.
\end{abstract}

(Received September 17, 1999; Accepted January 7, 2000)

\section{Introduction}

A number of workers have reported methods for the determination of ionic surfactants by direct potentiometry and potentiometric titration using surfactant-selective liquid membrane electrodes. ${ }^{1-14} \quad$ Surfactant-selective electrodes are also utilized for determining the activity of an ionic surfactant in the presence of polyelectrolytes in investigations of the interactions between the ionic surfactant and the polyelectrolyte. ${ }^{3-5}$ A liquid membrane or a plasticized poly(vinyl chloride) (PVC) membrane which incorporates an ion-pair of an ion-exchanger with an objective surfactant ion is usually used as the sensing membrane for surfactant ion-selective electrodes. ${ }^{2-5,7-14}$ In earlier studies, we reported that an electrode based on an $o$-nitrophenyl octyl ether (o-NPOE)-plasticized PVC membrane with no added ionexchanger showed a Nernstian response to cationic and anionic surfactants and several hydrophobic anions. ${ }^{15-17}$ The response mechanism of the $o$-NPOE-plasticized PVC membrane electrode to ionic surfactants is interesting in that the electrode shows a Nernstian response to ionic surfactants, in spite of the fact that no ion-exchanger is added to the sensing membrane.

$\doteqdot$ To whom correspondence should be addressed.
We estimated that the presence of small amount of cationic and anionic sites in the PVC and plasticizer and the selective adsorption or partition of ionic surfactants to the electrode membrane may be factors in the response characteristics of the electrode. In fact, Pungor and Buck et al. ${ }^{18-20}$ confirmed the presence of anionic sites in PVC membrane, based on measurements of ion-exchange capacity and the impedance of the plasticized PVC membrane and PVC powder. In addition, Bergveld et al. ${ }^{21}$ reported evidence for the presence of anionic sites in a plasticized PVC membrane, based on ESCA and X-ray fluorescence measurements. Recently, Pretsch et al. ${ }^{22}$ also determined the concentration of ionic impurities in PVC.

We examined the contribution of the plasticizer itself to the response of the plasticized PVC membrane electrode by using an ion-sensitive field-effect transistor (ISFET) in order to elucidate whether PVC or the plasticizer governs the response of the electrode to ionic surfactants. ${ }^{23}$ As a result, we were able to confirm that the contribution of the plasticizer, itself, to the response to ionic surfactants was very small, and that PVC, rather than the plasticizer, itself, played an important role in the response of the electrode to ionic surfactants. We also examined the relationship between the hydrophobicity of anionic surfactants and the response characteristics of the electrode to the anions in order to estimate the response mechanism of the electrode. ${ }^{24}$ 
This study reported on an evaluation of the hydrophobicity of the anions with reference to the selectivity coefficient of the PVC membrane electrode, which was based on an anion exchanger, and which was prepared using the same plasticizer as the electrode which was used to examine the response characteristics to the anions. This experiment was carried out because the selectivity coefficient of the liquid membrane electrode is known to be expressed by the ratio of the partition coefficient of anions between the membrane solvent and the aqueous phase. ${ }^{25,26}$ The findings show that the $o$-NPOE-plasticized PVC membrane electrode, with no added ion exchanger, showed a Nernstian response to the anions for which a chloride ion-selective PVC membrane electrode, based on an anion-exchanger, has a

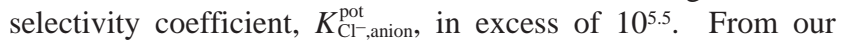
findings, it is concluded that the hydrophobicity of the anions, which parallels the partition of ions to the electrode membrane, is strongly related to the response characteristics of the electrode.

In this paper, we wish to report on the response behavior of the $o$-NPOE-plasticized PVC membrane electrode, which contains no ion exchanger, to a variety of cations, including tetraalkylammonium ions, alkyltrimethylammonium ions (cationic surfactants), as well as several inorganic and hydrophobic cations. Furthermore, the contribution of the plasticizer, itself, to the response of the above-mentioned electrode to the cations in detail by means of ISFET. The response mechanism of the $o$-NPOE-plasticized PVC membrane electrode to the cations is discussed based on the relationship between the response behavior of the electrode and the hydrophobicity of cations. The latter was evaluated via the selectivity coefficients, and from the response behavior of the ISFET electrode, based on the plasticizer, itself, to the cations.

\section{Experimental}

\section{Chemicals}

Tetraalkylammonium chlorides, alkyltrimethylammonium chlorides and bromides, hexadecylpyridinium chloride, trimethylbenzylammonium chloride and protonated methylammonium ion derivatives were of guaranteed grade and were obtained from Tokyo Kasei Ind. Co. Guaranteed-grade of benzyldimethylphenylammonium chloride was obtained from Wako Pure Chemicals Co. Tetradecyldimethylbenzylammonium chloride (Zephiramine) and tetraphenylphosphonium chloride were obtained from Dojindo Laboratories. Poly(vinyl chloride) (PVC) (degree of polymerization: 1100) was obtained from Wako Pure Chemicals Co. Sodium tetrakis(3,5-bis(trifluoromethyl)phenyl) borate (TFPB), dihydrate and $o$-NPOE were obtained from Dojindo Laboratories. All other reagents were of guaranteed grade.

\section{Preparation of plasticized PVC membrane with and without} ion-exchanger

The $o$-NPOE-plasticized PVC membrane with no added ionexchanger (membrane 1) was prepared as follows. $o$-NPOE (1.0 g) and PVC powder $(0.4 \mathrm{~g})$ were dissolved in tetrahydrofuran (THF). The resulting solution was poured onto a flat-bottomed glass dish. The THF was evaporated from the solution by standing at room temperature for $48 \mathrm{~h}$ to give a mother membrane. The thickness of the resulting PVC membrane was ca. $0.2 \mathrm{~mm}$. The PVC membrane containing TFPB as a cationexchanger (membrane 2) was also prepared in the same manner as described above. The composition of the membrane was $o$ NPOE (1.0 g), PVC (0.4 g) and TFPB (0.009 g).
Fabrication of the electrode and measurement of the membrane potential

A $0.6 \mathrm{~cm}$ diameter disk was cut from the mother membrane and attached to the end of a PVC chip (Denki Kagaku Keiki Co.) using a THF solution of PVC as an adhesive. A solution consisting of $5 \times 10^{-3} \mathrm{M} \mathrm{NaCl}$ and $5 \times 10^{-3} \mathrm{M}$ sodium dodecylsulfate ( $\mathrm{NaDS}$ ) and an $\mathrm{Ag}-\mathrm{AgCl}$ electrode were used as an inner solution and an inner reference electrode, respectively, for fabricating an electrode based on membrane 1 . The response behavior of the PVC membrane electrode to cations with different hydrophobicity was examined by measurement of the electromotive force (emf) of the following electrochemical cell assembly.

(-) $\mathrm{Ag} / \mathrm{AgCl} / 3 \mathrm{M} \mathrm{KCl} / 1 \mathrm{M} \mathrm{CH}_{3} \mathrm{COOLi} /$ sample solution // PVC membrane / inner solution $\left(5 \times 10^{-3} \mathrm{M} \mathrm{NaDS}-5 \times 10^{-3} \mathrm{M}\right.$ $\mathrm{NaCl}) / \mathrm{AgCl} / \mathrm{Ag}(+)$

The emfs were measured for 20 min for one sample solution and the emf values, which variation with time reached at 0.5 $\mathrm{mV} / \mathrm{min}$, were adopted. In general, the stable emf was obtained within $10 \mathrm{~min}$, and the variation of emf with time was very small. Furthermore, the emfs were measured at least twice for the same sample, and emf values were reproducible within \pm 2 $\mathrm{mV}$. The $\mathrm{pH}$ of the sample solution was not adjusted, and no supporting electrolyte was added to the sample solution. A sodium ion-selective electrode was fabricated by using membrane 2 in order to obtain the selectivity coefficients of the electrode to the sodium ion against the cations, $K_{\mathrm{Na}^{+}, \text {cation. }}^{\text {pot }}$ The solution of $10^{-2} \mathrm{M} \mathrm{NaCl}$ was used as the inner solution of the $\mathrm{Ag}-\mathrm{AgCl}$ reference electrode. The selectivity coefficients, $K_{\mathrm{Na}^{+}, \text {cation, }}^{\text {pot }}$ were evaluated by using the separate solution method. ${ }^{27}$

\section{Response of the ISFET electrode based on pure plasticizer membrane to cations}

The fabrication of the ISFET electrode was performed in the same manner as described in our previous paper. ${ }^{23}$ The ISFET electrode consisted of a glass capillary ( $c a .1 \mathrm{~mm}$ inside diameter, ca. $2 \mathrm{~cm}$-long, the tip was reduced to $c a .0 .4 \mathrm{~mm}$ in diameter), which was filled with a plasticizer, $o$-NPOE, and a $\mathrm{pH}$-sensitive FET (Shindengen Co., Japan, $340 \mu \mathrm{m} \times 5500 \mu \mathrm{m}$ $\times 200 \mu \mathrm{m}^{\mathrm{t}}$ ) whose gate was directly soaked in the plasticizer. $O$ NPOE was purified by distillation under reduced pressure. The response of the ISFET electrode to cations was examined by measuring the emf of the following electrochemical cell with an ISFET $/ \mathrm{mV}$ meter (Shindengen Co.) at $25 \pm 3^{\circ} \mathrm{C}$.

(-) $\mathrm{Ag} / \mathrm{AgCl} / 3 \mathrm{M} \mathrm{KCl} / 1 \mathrm{M} \mathrm{CH}_{3} \mathrm{COOLi} / /$ sample solution $/$ plasticizer (o-NPOE) / FET (+)

The emfs of the ISFET electrode were measured in the same manner as for the measurements using the PVC membrane electrode. The $\mathrm{pH}$ and ionic strength of the sample solution were not adjusted in the same manner as for the measurements using the PVC membrane electrode.

\section{Results and Discussion}

Evaluation of hydrophobicity of cations by the selectivity coefficients of the sodium ion-selective PVC membrane electrode based on cation-exchanger

In general, the selectivity of an ion-exchange liquid membrane electrode is mainly governed by the partition coefficient of ions between the electrode membrane and an aqueous solution, since 


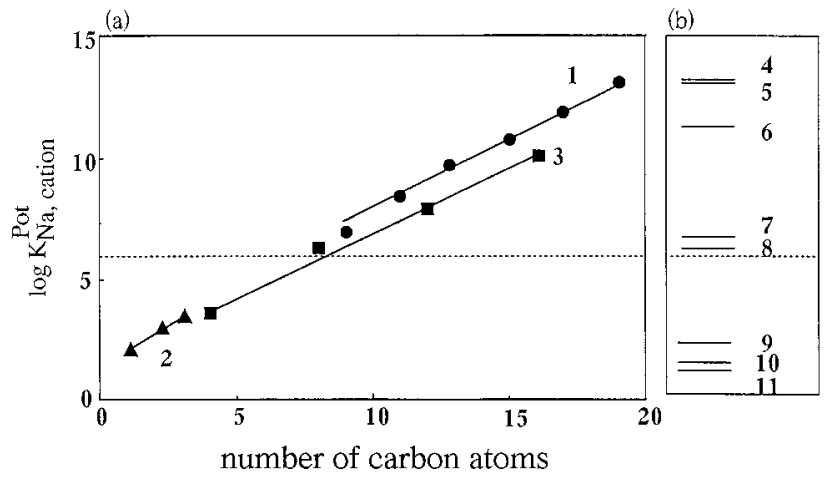

Fig. 1 Selectivity coefficients of a sodium ion-selective electrode based on $o$-nitrophenyl octyl ether-plasticized PVC membrane to cations. (a) Selectivity coefficients for alkyltrimethylammonium ions, protonated methylammonium ion derivatives and tetraalkylammonium ions. 1 alkyltrimethylammonium ions (co-ion: $\mathrm{Br}^{-}$ion): 9 (number of carbon atoms), hexyltrimethylammonium ion; 11 , octyltrimethylammonium ion; 13 , decyltrimethylammonium ion; 15, dodecyltrimethylammonium ion; 17, tetradecyltrimethylammonium ion; 19, hexadecyltrimethylammonium ion. $\mathbf{2}$ protonated methylammonium ion derivatives (co-ion: $\mathrm{Cl}^{-}$ion): 1 (number of carbon atoms), methylammonium ion; 2 , dimethylammonium ion; 3 , trimethylammonium ion. 3 tetraalkylammonium ions (co-ion: $\mathrm{Cl}^{-}$ion); 4 (number of carbon atoms), tetramethylammonium ion; 8 , tetraethylammonium ion; 12, tetrapropylammonium ion; 16 , tetrabutylammonium ion. (b) Selectivity coefficients for hydrophobic and inorganic cations (coion: $\mathrm{Cl}^{-}$ion): $\mathbf{4}$, tetradecyldimethylbenzylammonium ion; $\mathbf{5}$, tetraphenylphosphonium ion; 6, hexadecylpyridinium ion; 7, benzyldimethylphenylammonium ion; 8 , trimethylbenzylammonium ion; $\mathbf{9}, \mathrm{Cs}^{+}$ion; 10, $\mathrm{K}^{+}$ion; $\mathbf{1 1}, \mathrm{NH}_{4}{ }^{+}$ion.

the mobility of ions in the membrane is similar for all ions. ${ }^{25}$ Therefore, the following equation holds for such an electrode:

$$
K_{\mathrm{i}, \mathrm{j}}^{\mathrm{pot}} \cong \frac{k_{\mathrm{i}}}{k_{\mathrm{j}}}
$$

where $K_{\mathrm{i}, \mathrm{j}}^{\mathrm{pot}}$ is the selectivity coefficient of the i-ion selective electrode for the i-ion against to the $\mathrm{j}$-ion, $k_{\mathrm{i}}$ and $k_{\mathrm{j}}$ are the partition coefficients of the ions $\mathrm{i}$ and $\mathrm{j}$, respectively. It has been experimentally verified that the selectivity coefficients of cation- and anion-exchange liquid membrane electrodes are correlated with the partition coefficients of ions, which were obtained by liquid-liquid extraction. ${ }^{28,29}$ Since the partition property of ions is related to their hydrophobicity, the hydrophobicity can be evaluated by the selectivity coefficients of the ion-exchange liquid membrane electrode. To obtain this, we measured the selectivity coefficients of a sodium ionselective electrode based on membrane 2 for a series of alkyltrimethylammonium ions (cationic surfactants), tetraalkylammonium ions and inorganic cations, with reference to sodium ion. Figure 1 (a) shows the relationship between the $\operatorname{logarithm}$ of the selectivity coefficient $\left(\log K_{\mathrm{Na} \text {,cation }}^{\mathrm{pot}}\right)$ for alkyltrimethylammonium ions (cationic surfactants), tetraalkylammonium ions and protonated methylammonium ion derivatives and the number of carbon atoms contained by such ions. The selectivity coefficients for several hydrophobic and inorganic cations are also shown in Fig. 1 (b). The selectivity coefficients for alkyltrimethylammonium ions and tetraalkylammonium ions increase regularly and logarithmically with an increase in the number of carbon atoms in their cations. The slope of the straight line is 0.63 per carbon atom for alkyltrimethylammonium ions and 0.54 per carbon atom for tetraalkylammonium ions, respectively.

Motomizu $^{30,31}$ systematically measured ion-pair extraction constants of cationic and anionic surfactants between water and several organic solvents and proposed a general equation which expresses a relationship between logarithm of the extraction constant $\left(\log K_{\mathrm{ex}}\right)$ and parameters $C$ and $A$, as follows:

$$
\log K_{\mathrm{ex}}=C+A
$$

where the parameters $C$ and $A$ are the relative extractabilities of the cations and anions, respectively, for extraction of the ionpair. In addition, Motomizu concluded that for the ion-pair extraction of cationic surfactants with the same anion, a linear relationship between the $C$ values and the number of carbon atoms in the cationic surfactants exists. A straight line having a slope of 0.59 for a plot of $\log K_{\text {ex }}$ versus the number of carbon atoms of the cationic surfactants was obtained. This relationship is similar to that between $\log K_{\mathrm{Na}^{+}, \text {cation }}^{\text {pot }}$ and the number of carbon atoms in the alkylammonium ions obtained in the present work. From the comparison of Motomizu's results with ours, it is concluded that the logarithm of the extraction constant $\left(\log K_{\mathrm{ex}}\right)$ for cations is strongly related to the logarithm of the selectivity coefficient $\left(\log K_{\mathrm{Na}^{+}, \text {cation }}^{\mathrm{pot}}\right)$. This suggests that the selectivity coefficient obtained by the PVC membrane electrode is a good measure of extractability, and thus the hydrophobicity of ions.

The response characteristics of o-NPOE-plasticized PVC membrane electrode with no added ion-exchanger to cations

The potential responses of the $o$-NPOE-plasticized PVC membrane electrode based on membrane 1 to alkyltrimethylammonium ions (cationic surfactants), tetraalkylammonium ions, some organic cations, protonated methylammonium ions and common inorganic cations are shown in Fig. 2. As shown in Fig. 2 (a), the electrode exhibits a Nernstian response to alkyltrimethylammonium ions containing from nine to seventeen carbon atoms over the concentration range from $10^{-5}$ to $10^{-2} \mathrm{M}$. For decyltrimethylammonium $\left(\mathrm{DTA}^{+}\right)$and dodecyltrimethylammonium (DoTA ${ }^{+}$) ions ((3) and (4) in Fig. 2 (a)), the deviation from a Nernstian response is observed for concentrations higher than $10^{-2} \mathrm{M}$. This phenomenon is due to micelle formation of the cationic surfactants $\left(\mathrm{DTA}^{+}\right.$and $\left.\mathrm{DoTA}^{+}\right)$at concentrations higher than $10^{-2} \mathrm{M}$, judging from the critical micelle concentrations of $\mathrm{DTA}^{+}$and DoTA ${ }^{+}$reported to be $6.8 \times 10^{-2} \mathrm{M}$ and $1.6 \times 10^{-2} \mathrm{M}$, respectively. ${ }^{32}$

The electrode shows a Nernstian response to tetradecyltrimethylammonium and hexadecyltrimethylammonium ions in the concentration range from $10^{-5}$ to $10^{-2} \mathrm{M}, 10^{-5}$ to $10^{-2}$ M, respectively ((1) and (2) in Fig. 2 (a)). However, in the concentration range from $10^{-6}$ to $10^{-5} \mathrm{M}$, the electrode shows a super-Nernstian response to both ions. In general, the superNernstian response to a hydrophobic ion is observed for the liquid membrane-type electrodes when the concentration of an ion-exchanger in the electrode membrane is higher than that of the objective ion in the sample solution. ${ }^{26,28}$ In such a situation, the objective ion existing in the sample solution at low concentration is easily exchanged with a counter ion of the ionexchanger in the electrode membrane. ${ }^{26}$ This ion exchange reaction reduces the concentration of the objective ion in the vicinity of the electrode membrane. Therefore, this superNernstian response suggests the presence of anionic sites or anionic species in the PVC or the plasticizer of the electrode membrane. 
(a)

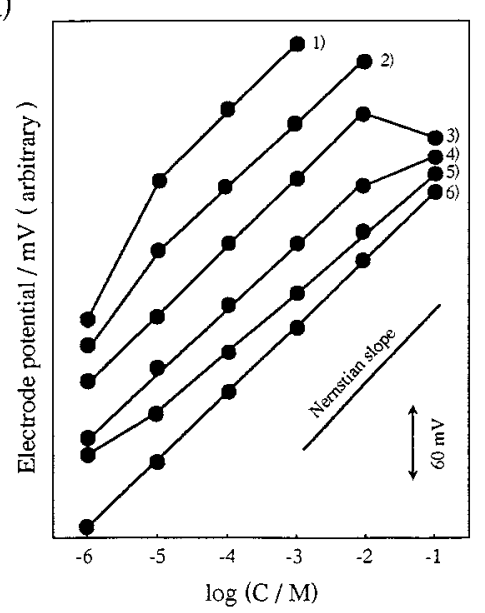

(c)

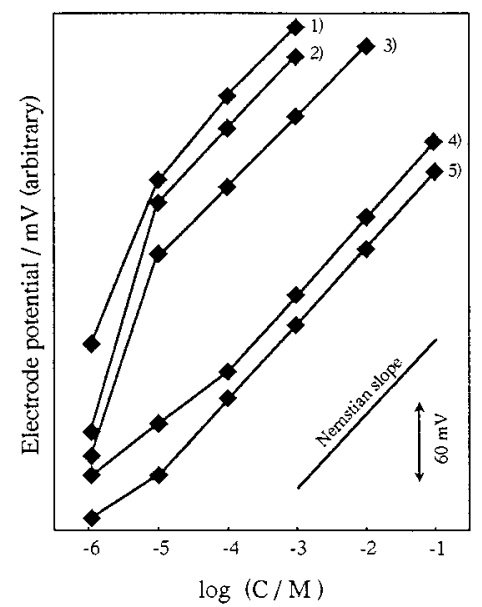

(b)

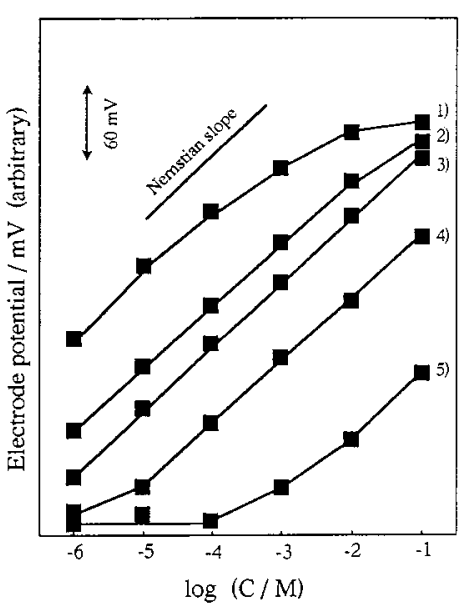

(d)

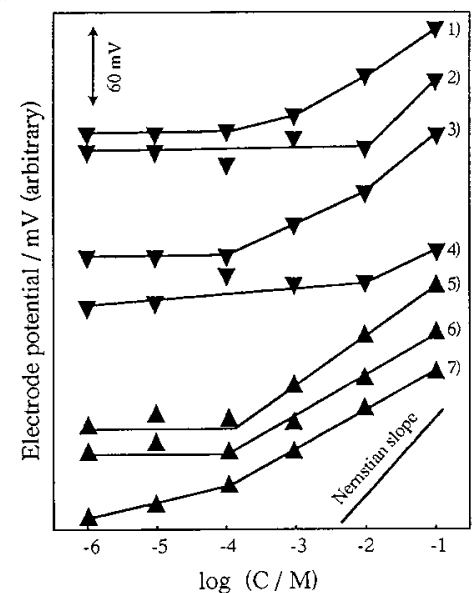

Fig. 2 Potential response of $o$-nitrophenyl octyl ether-plasticized PVC membrane electrode with no added cation exchanger to cations. (a) alkyltrimethylammonium ions (co-ion: $\mathrm{Br}^{-}$ion): 1, hexadecyltrimethylammonium ion; 2, tetradecyltrimethylammonium ion; 3 , dodecyltrimethylammonium ion; 4, decyltrimethylammonium ion; 5, octyltrimethylammonium ion; 6, hexyltrimethylammonium ion. (b) tetraalkylammonium ions (co-ion: $\mathrm{Cl}^{-}$ion): 1 , tetrapentylammonium ion; 2 , tetrabutylammonium ion; 3 , tetrapropylammonium ion; 4, tetraethylammonium ion; 5, tetramethylammonium ion. (c) hydrophobic cations (co-ion: $\mathrm{Cl}^{-}$ion): 1, tetradecyldimethylbenzylammonium ion (Zephiramine); 2, hexadecylpyridinium ion; 3, tetraphenylphosphonium ion; 4, trimethylbenzylammonium ion; 5, benzyldimethylphenylammonium ion. (d) protonated methylammonium ion derivatives and common inorganic cations (co-ion: $\mathrm{Cl}^{-}$ion): $1, \mathrm{Na}^{+}$ion; 2, $\mathrm{K}^{+}$ion; 3, $\mathrm{Cs}^{+}$ion; 4, $\mathrm{Ca}^{2+}$ ion; 5, methylammonium ion; 6, dimethylammonium ion; 7, trimethylammonium ion.

The potential responses of the $o$-NPOE-plasticized PVC membrane electrode based on membrane 1 to tetraalkylammonium ions are also shown in Fig. 2 (b). The electrode does not show a Nernstian response to tetramethylammonium ion (Fig. 2 (b) (5)), but does so for the case of other tetraalkylammonium ions having in excess of eight carbon atoms, except for tetrapentylammonium ion at the higher concentration than $10^{-4}$ M, as is seen in Fig. 2 (b) ((1) - (4)). The potential response of the electrode to tetrapentylammonium ion deviates from a Nernstian response at concentrations higher than $10^{-4} \mathrm{M}$. The deviation is remarkable in the concentration range from $10^{-2}$ to $10^{-1} \mathrm{M}$. The reason for the sub-Nernstian response to tetrapentylammonium ion is not clear at present, but the invasion of chloride into the electrode membrane, accompanied by tetrapentylammonium ion, due to its large hydrophobicity may reduce the permselectivity of the electrode membrane.
This may be due to the fact that anionic site in the electrode membrane is not sufficient to exclude chloride in the higher concentration of the sample solution.

A Nernstian response was observed for some hydrophobic cations in the concentration range from $10^{-5} \mathrm{M}$ to $10^{-3} \mathrm{M}$ or to $10^{-1} \mathrm{M}$, as shown in Fig. 2 (c). The measurements for tetradecyldimethylbenzylammonium, hexadecylpyridinium and tetraphenylphosphonium ions in the higher concentration range than $10^{-3}$ or $10^{-2} \mathrm{M}$ were limited by the solubility of the sample salts. The electrode shows a super-Nernstian response to tetradecyldimethylbenzylammonium ion, hexadecylpyridinium ion and tetraphenylphosphonium ion in the concentration range from $10^{-6}$ to $10^{-5} \mathrm{M}$ (Fig. 2 (c), (1) - (3)). This response behavior can be explained by the same consideration as described for Fig. 2 (a) ((1) and (2)). As shown in Fig. 2 (d), the electrode based on membrane 1 shows a poor response to inorganic cations and 


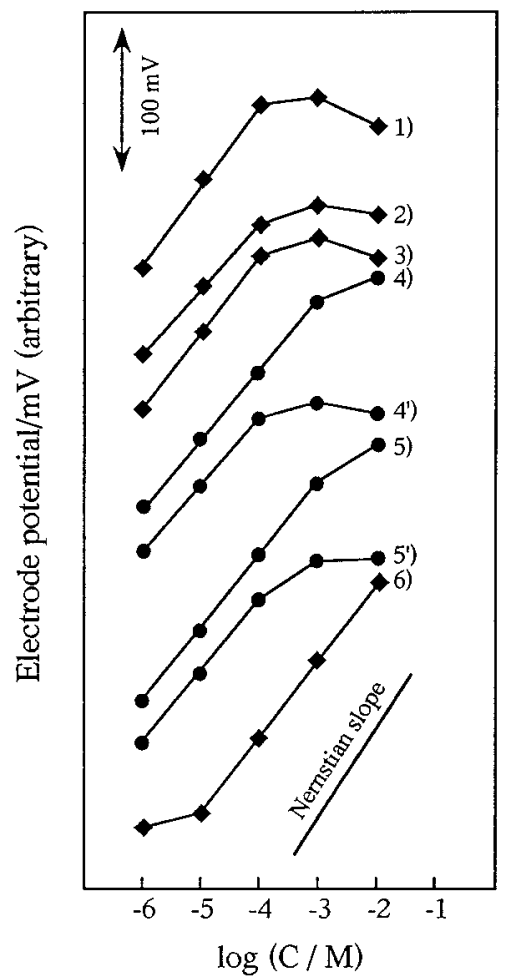

Fig. 3 Potential response of the ISFET electrode, based on $o$ nitrophenyl octyl ether, to several cations. 1, tetradecyldimethylbenzylammonium ion (co-ion: $\mathrm{Cl}^{-}$); 2, tetraphenylphosphonium ion (co-ion: $\mathrm{Cl}^{-}$); 3, hexadecylpyridinium ion (co-ion: $\mathrm{Cl}^{-}$); 4, dodecyltrimethylammonium ion (co-ion: $\left.\mathrm{Cl}^{-}\right) ; 4^{\prime}$, dodecyltrimethylammonium ion (co-ion: $\mathrm{Br}$ ); 5, decyltrimethylammonium ion (co-ion: $\mathrm{Cl}^{-}$); $5^{\prime}$ decyltrimethylammonium ion (co-ion: $\mathrm{Br}^{-}$); 6 , benzyldimethylphenylammonium ion (co-ion: $\left.\mathrm{Cl}^{-}\right)$.

protonated methylammonium ions. Summarizing the response properties of the $o$-NPOE-plasticized PVC membrane electrode based on membrane 1 to the cations, we can conclude that the electrode shows a Nernstian response to the cations, which are plotted on the upper side of the dotted line at $\log K_{\mathrm{Na}^{+}, \text {,ation }}^{\text {pot }}=6.0$ in Fig. 1. This indicates that the electrode responds to cations which are more hydrophobic than sodium ion by at least $10^{6}$ fold, as estimated from the selectivity coefficients of the sodium ion-selective electrode based on membrane 2 .

The response behavior of the ISFET electrode based on plasticizer itself to cations

We compared the response of the ISFET electrodes which were fabricated using both purified and unpurified $o$-NPOE. No significant difference in the response of the ISFET electrodes was observed. As a result, subsequent experiments were performed using unpurified $o$-NPOE.

Figure 3 shows the response of the ISFET electrode based on $o$-NPOE to several cations. A near-Nernstian response is observed for the cations shown in Fig. 3, although the concentration range of the linear part is different for each cation. On the other hand, the ISFET electrode did not show a Nernstian response to inorganic cations such as sodium ion (data are not shown). In the response of the ISFET electrode to the cations having the same co-ion, a $\mathrm{Cl}^{-}$ion, the concentration of upper detection limit becomes lower with increasing hydrophobicity of the cations, as shown in Fig. 3 ((1), (2), (3), (4), (5) and (6)). For example, the ISFET electrode shows a Nernstian response to the benzyldimethylphenylammonium ion up to $10^{-2} \mathrm{M}$ (Fig. 3 (6)), but the deviation from the Nernstian response is observed for the response to tetradecyldimethylbenzylammonium ion at $10^{-4} \mathrm{M}$ (Fig. 3 (1)). The selectivity coefficients of the sodium ion-selective electrode are $10^{7}$ and $10^{13}$ against the former and the latter ion, respectively (Fig. 1 (4) and (7)). The data in Fig. 3 suggest that the hydrophobicity of the cations appears to affect the response of the ISFET electrode based on plasticizer itself.

In spite of the addition of no ion-exchanger to $o$-NPOE, it is interesting that the ISFET electrode based on $o$-NPOE shows a Nernstian response in a limited concentration range, depending on the hydrophobicity of the cations. The Nernstian response of the ISFET electrode suggests that the sensing membrane, in this case, $o$-NPOE, may contain an anionic species which acts as a cation exchanger and an anion excluder. The deviation from the Nernstian response which is observed at higher concentrations of cation also suggests that the concentration of the anionic species in the membrane may be very low and is not sufficient to exclude the invasion of the co-ion into the membrane. Successful measurements of the ISFET electrode based on $o$ NPOE are due to the excellent advantage of the ISFET, which can be used for membranes with an extremely high impedance.

Another interesting response of the ISFET electrode is the effect of a co-ion. The response of the ISFET electrode to dodecyltrimethylammonium $\left(\mathrm{DoTA}^{+}\right)$ion at concentrations higher than $10^{-4} \mathrm{M}$ is dependent on the type of counter ion of the DoTA ${ }^{+}$ion, as shown in Fig. 3 (4) and (4'). Namely, the deviation from the linear response was observed at lower concentration when the counter ion was $\mathrm{Br}^{-}$ion, rather than $\mathrm{Cl}^{-}$ ion. Since $\mathrm{Br}^{-}$ion is more hydrophobic than $\mathrm{Cl}^{-}$ion, the $\mathrm{Br}$ ion, even at lower concentration might invade the electrode membrane easier than $\mathrm{Cl}^{-}$ion when the concentration of an anion excluder in the electrode membrane is not sufficient. Therefore, the fact that the linear concentration range in the response of the ISFET electrode to the cations was narrower when $\mathrm{Br}^{-}$ion was used as a co-ion instead of $\mathrm{Cl}^{-}$ion, suggests that an anionic species is present in the $o$-NPOE membrane, which acts as a cation-exchanger, and that the content of the anionic species is very low.

Comparison of potential response of o-NPOE-plasticized PVC membrane electrode with that of ISFET electrode based on oNPOE

The potential responses of the $o$-NPOE-plasticized PVC membrane electrode based on membrane 1 and the ISFET electrode based on $o$-NPOE to alkyltrimethylammonium ions are shown in Fig. 4. An ion exchanger was not added to the sensing membrane of both electrodes. The difference between the two electrodes is the presence of PVC in the sensing membrane for the former electrode but absence of PVC for the latter electrode. Both electrodes show a Nernstian response to alkyltrimethylammonium ions in the lower concentration range, but the response behavior in the higher concentration range is different for each electrode, as shown in Fig. 4. For example, the Nernstian response to dodecyltrimethylammonium ion is observed for the $o$-NPOE-plasticized PVC membrane electrode up to $10^{-2} \mathrm{M}$ (Fig. 4 (2)). On the other hand, deviation from the Nernstian response is observed for the ISFET electrode in the higher concentration range from $10^{-4} \mathrm{M}$ to $10^{-2} \mathrm{M}$ (Fig. 4 (2') and $\left.\left(2^{\prime \prime}\right)\right)$. Therefore, the origin of difference in the response of the two electrodes is the presence or absence of PVC in the sensing membrane. As mentioned previously, the response of the ISFET electrode based on $o$-NPOE to cations was affected by the types of co-ions of the cations. In particular, the deviation from the Nernstian response occurred at lower concentration when 

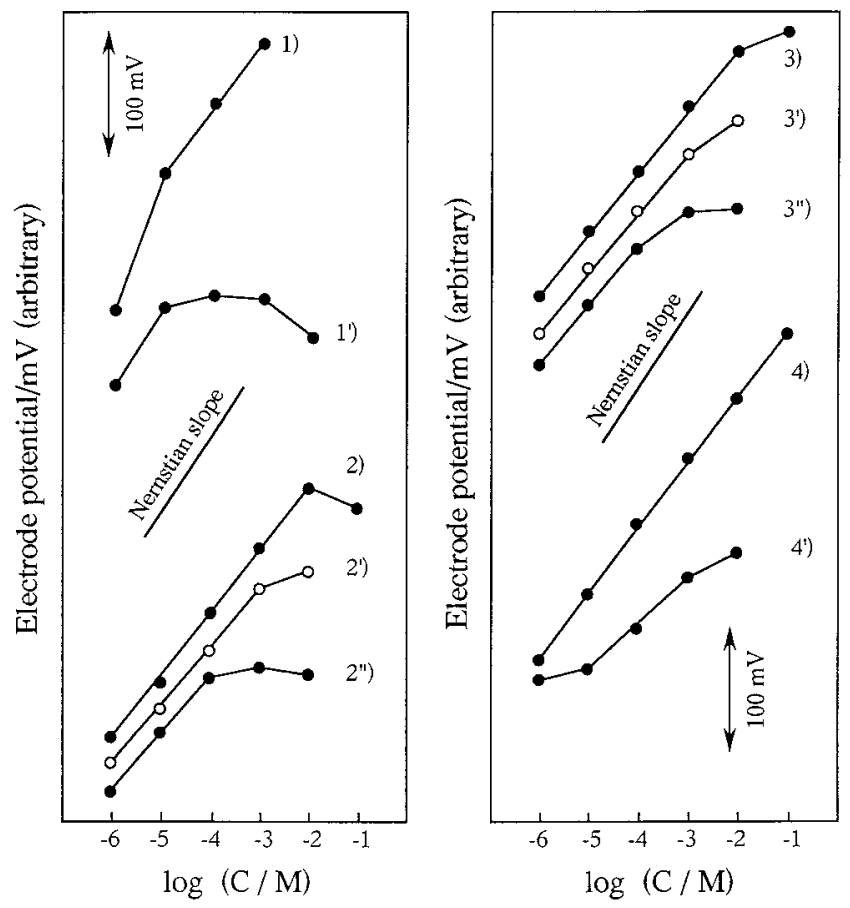

Fig. 4 Comparison of the potential response of the ISFET electrode, based on $o$-nitrophenyl octyl ether, with the plasticized PVC membrane electrode to alkyltrimethylammonium cations. (1), (2), (3), (4): potential response of the plasticized PVC membrane electrode. $\left(1^{\prime}\right),\left(2^{\prime}\right),\left(2^{\prime \prime}\right),\left(3^{\prime}\right),\left(3^{\prime \prime}\right),\left(4^{\prime}\right)$ : potential response of the ISFET electrode. Co-ion: $\bullet, \mathrm{Br}^{-}$ion; $\mathrm{O}, \mathrm{Cl}^{-}$ion. Cations: (1), $\left(1^{\prime}\right)$, hexadecyltrimethylammonium ion; (2), (2'), (2"), dodecyltrimethylammonium ion; (3), (3'), (3"), decyltrimethylammonium ion; (4), (4'), hexyltrimethylammonium ion.

the $\mathrm{Br}^{-}$ion was the co-ion. On the other hand, the $o$-NPOEplasticized PVC membrane electrode based on membrane 1 shows a Nernstian response to the cations, even when the co-ion is $\mathrm{Br}^{-}$ion. A deviation from Nernstian response was not observed for the $o$-NPOE-plasticized PVC membrane electrode based on membrane 1, even when the co-ion was $\mathrm{Br}^{-}$ion. These findings may also be explained by the fact that exclusion of the co-ion is effected by the presence of anionic sites in the PVC membrane, which was confirmed by Bergveld et al. ${ }^{21}$ Bergveld et al. ${ }^{21}$ estimated that the anionic sites in PVC may be anionic surfactants, which originates from a residual surfactant used in the process of PVC production. Therefore, the fact that the $o$ NPOE-plasticized PVC membrane electrode shows a Nernstian response to alkyltrimethylammonium ions in a higher concentration range up to $10^{-2}$ or $10^{-1} \mathrm{M}$ is due to the fact that the co-ion is excluded completely by the anionic sites in PVC because these sites may be more hydrophobic than the co-ion, $\mathrm{Cl}^{-}$or $\mathrm{Br}$ ion in the sample solution.

Response mechanism of the o-NPOE-plasticized PVC membrane electrode based on membrane 1 to the cations

Figure 5 shows a plausible response mechanism for the $o$ NPOE-plasticized PVC membrane electrode with no added ionexchanger to the hydrophobic cations. Response mechanism shown in Fig. 5 involves the presence of anionic, $\mathrm{R}^{-}$, and cationic species, $\mathrm{R}^{+}$, in the membrane assisting an ion-exchange reaction between the cationic species, $\mathrm{R}^{+}$, and hydrophobic cations in the sample solution. In this case, the anionic species, $\mathrm{R}^{-}$, acts as a cation exchanger, excluding the invasion of the co-

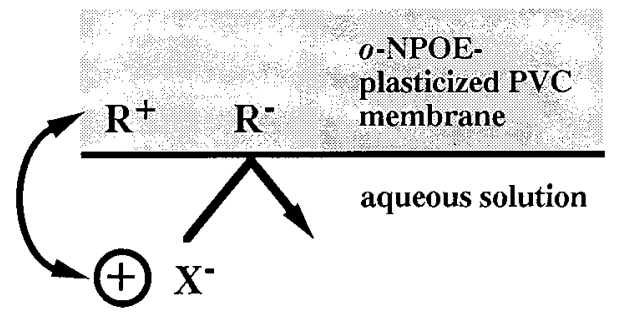

\author{
( : hydrophobic cation \\ $\mathrm{R}^{+}$: cationic site \\ $\mathbf{R}^{-}$: anionic site \\ $\mathrm{X}^{-}$: co-ion
}

Fig. 5 Response mechanism of the plasticized PVC membrane electrode to hydrophobic cations.

ion, $\mathrm{X}^{-}$, into the membrane. The charge separation, which is due to exclusion of the co-ion by the anionic species in the membrane, is the origin of the electrode response. The presence of some anionic sites has been confirmed by many researchers, as described in the previous section, but the presence of a cationic site in PVC has not yet been confirmed experimentally. As mentioned in the section on the comparison of responses of the $o$-NPOE-plasticized PVC membrane electrode with those of the ISFET electrode based on $o$-NPOE, we estimated the presence of an anionic species in the $o$-NPOE plasticizer from the response behavior of the ISFET electrode based on $o$-NPOE. In spite of the purification of $o$-NPOE by distillation, some anionic species may be still present in the plasticizer at very low levels. The chemical form of the anionic species is not clear but it might be a starting compound or decomposed species from the synthesis of $o$-NPOE. The estimation of the presence of anionic sites in PVC is not unrealistic, but is possible from the result that the co-ion exclusion of the $o$-NPOE-plasticized PVC membrane was more effective than that of the $o$-NPOE membrane.

The ion-exchange reaction between the cationic species, $\mathrm{R}^{+}$, and the objective cation can be complete, if the hydrophobicity of the objective cation is sufficiently larger than that of $\mathrm{R}^{+}$. The $o$-NPOE-plasticized PVC membrane electrode shows a Nernstian response to hydrophobic cations, which has a larger hydrophobicity than sodium ion by $10^{6}$ fold, as described in the previous section. The hydrophobicity of the cationic species $\mathrm{R}^{+}$ is estimated to be $10^{6}$ fold larger than sodium ion. This may be the reason why the $o$-NPOE-plasticized PVC membrane electrode shows poor response to cations with a selectivity coefficient less than $10^{6}$, because the ion exchange reaction between the cationic species $\mathrm{R}^{+}$in the membrane and the cations with the selectivity coefficient less than $10^{6}$ do not take place easily. Therefore, we wish to propose the response mechanism shown in Fig. 5 for the $o$-NPOE-plasticized PVC membrane electrode.

\section{References}

1. M. M. Khalil, D. F. Anghel, and C. Luca, Anal. Lett., 1986, 19, 807.

2. I. Satake, S. Noda, and T. Maeda, Bull. Chem. Soc. Jpn., 1983, 56, 2581.

3. G. C. Kresheck and I. Constantinidis, Anal. Chem., 1984, 
56,152

4. B. J. Birch and D. E. Clarke, Anal. Chim. Acta, 1973, 67, 387.

5. B. J. Birch and D. E. Clarke, Anal. Chim. Acta, 1974, 70, 417.

6. T. Maeda, M. Ikeda, M. Shibahara, T. Haruta, and I. Satake, Bull. Chem. Soc. Jpn., 1981, 54, 94.

7. A. Yamauchi, T. Kunisaki, T. Minematsu, Y. Tomokiyo, T. Yamaguchi, and H. Kimizuka, Bull. Chem. Soc. Jpn., 1978, $51,2791$.

8. S. G. Cutler, P. Meares, and D. G. Hall, J. Electroanal. Chem., 1977, 85, 145.

9. N. Ishibashi and H. Kohara, Bunseki Kagaku, 1972, 21, 100.

10. M. Kataoka and T. Kambara, Denki Kagaku, 1975, 43, 209.

11. M. Kataoka, S. Ueda, and T. Kambara, Nippon Kagaku Kaishi, 1980, 1442.

12. T. Kobayashi, M. Kataoka, and T. Kambara, Talanta, 1980, 27, 253

13. K. M. Kale, E. L. Cussler, and D. F. Evans, J. Phys. Chem., 1980, 84, 593.

14. H. Hara, S. Okazaki, and T. Fujinaga, Nippon Kagaku Kaishi, 1980, 1645.

15. T. Masadome, T. Imato, and N. Ishibashi, Anal. Sci., 1987, 3,121 .

16. N. Ishibashi, T. Masadome, and T. Imato, Anal. Sci., 1986, $2,487$.

17. T. Masadome, T. Imato, and N. Ishibashi, Bunseki Kagaku, 1987, 36, 508.

18. G. Horvai, E. Gráf, K. Tóth, E. Pungor, and R. P. Buck,
Anal. Chem., 1986, 58, 2735.

19. K. Tóth, E. Gráf, G. Horvai, E. Pungor, and R. P. Buck, Anal. Chem., 1986, 58, 2741.

20. E. Linder, E. Gráf, Z. Niegreisz, K. Tóth, E. Pungor, and R. P. Buck, Anal. Chem., 1988, 60, 295.

21. A. van der Berg, P. D. van del Wal, M. SkowronskaPtásinska, E. J. R. Sudhölter, D. N. Reinhoudt, and P. Bergveld, Anal. Chem., 1987, 59, 2827.

22. M. Nägele and E. Pretsch, Mikrochim. Acta, 1995, 121, 269.

23. T. Masadome, S. Wakida, Y. Kawabata, T. Imato, and N. Ishibashi, Anal. Sci., 1992, 8, 89.

24. T. Masadome, J. G. Yang, T. Imato, and N. Ishibashi, Bunseki Kagaku, 1992, 41, 231.

25. J. Sandblom, G. Eisenman, and J. L. Walker Jr., J. Phys. Chem., 1967, 71, 3862.

26. W. E. Morf, "The principles of Ion-Selective Electrodes and Membrane Transport", 1981, Elsevier, Amsterdam.

27. G. J. Moody and J. D. R. Thomas, "Selective Ion Sensitive Electrodes", 1971, Merrow, Watford Herts.

28. A. Jyo, M. Torikai, and N. Ishibashi, Bull. Chem. Soc. Jpn., 1974, 47, 2862.

29. R. Scholer and W. Simon, Helv. Chim. Acta, 1973, 55, 1801.

30. S. Motomizu, Bunseki Kagaku, 1984, 33, 31.

31. S. Motomizu, Bunseki Kagaku, 1989, 38, 147.

32. M. J. Rosen, "Surfactants and Interfacial Phenomena", 1978, Wiley-Interscience. 